\title{
ALÉM, MUITO ALÉM DAS CONVERGÊNCIAS ENTRE A ADMINISTRAÇÃO E A GESTÃO DA EDUCAÇÃO
}

\section{Very Very Much Beyond Convergent Issues Between Administration And Education}

\author{
Antonio Semeraro Rito Cardoso ${ }^{1}$ \\ Paulo Reis Vieira ${ }^{2}$
}

\section{Resumo}

O objetivo deste trabalho é analisar a associação entre administração e educação, a fim de clanificar a integração entre elas, partindo do pressuposto de que a liberdade constitui fator indispensável ao desenvolvimento político, social e humano. Verificou-se que essa associação só se observa se assumidas por ambas as partes, práticas libertárias. A essa conclusão chegou-se por meio de revisão de literatura pertinente, com ênfase em autores ideologicamente posicionados a favor da liberdade como valorinerente ao humano do ser. Foi proposto modelo de gestão libertária com suas dimensões básicas - integração, qualidade e valores -, visualizando-se como indispensável a liberdade em organizações/ espaços educacionais. Também foram utilizados depoimentos verbais e escritos de participantes de cursos ministrados pelos pesquisadores em 2001/02 e pesquisa feita em espaço educacional, no caso a Secretaria Municipal de Educação do Rio de Janeiro (SME/RJ). O trabalho demonstra, em grande parte, que os pontos de encontro entre administração e educação vão muito além de simples convergências entre elas, já que a liberdade pertence à essência dos processos administrativos e educacionais.

Palavras-chave: Gestão da educação; Valores organizacionais; Administração da educação.

1 Mestre em Administração Pública pela EBAPE/FGV. Especialista em Ciência Política pelo Instituto Metodista Bennett. Graduado em Economia pela Universidade Cândido Mendes. Técnico de Planejamento e Pesquisa pelo IPEA. Professor da FGV/EBAPE. Coordenador de Apoio Técnico e Administrativo - DIPES/RJ

Endereço: Rua Garibaldi 145, ap. 501, Tijuca - 20511-330 - Rio de Janeiro-RJ

2 Ph.D. em Administração Pública pela USC, USA. Professor da Fundação Getúlio Vargas.

Endereço: Rua Senador Vergueiro, 185 - Apartamento 602 - Flamengo - 22.230-000 - Rio de Janeiro 


\section{Abstract}

This paper aims at analizing the interdisciplinary association between administration and education under the assumption that freedom and liberty are essential to political, social and human development. This association can only exist if managers and educators accept freedom and liberty in their daily practices. Such a conclusion has been arrived at by reviewing the literature produced by authors who have emphasized freedom and liberty as inerent values to human beings. A model based on freedom and liberty was built both for administrators and educators. Data were collected from interviews with students in courses taught by the authors and by department heads in the municipal education agency in Rio de Janeiro. The main conclusion is that the association between administration and education goes beyond simple common missions and objectives. Due to the fact that freedom and liberty are essential to development in both fields, administration and education are really integrated and unassociated.

Keywords: management of the education, organizationals values, administration and education.

\section{Iniciando a Reflexão}

Começamos pela afirmativa categórica de que resulta o fio condutor para este trabalho: administração é ciência social aplicada. Esse entendimento justifica, em primeiro lugar, o próprio título deste estudo. Traduz, também, o esforço necessário para tratamento antifragmentário das diversas áreas de conhecimento que cuidam da condição humana e das práticas delas conseqüentes e atenta para o instrumental e, sobretudo, para o substantivo. O singular ciência social - em substituição ao contumaz plural - ciências sociais - sinaliza compreensão mais abrangente e integradora do fenômeno administrativo. Já não basta explicitar que administrar significa adequar meios a fins para garantir eficiência de procedimentos e eficácia de resultados.

A discussão teleológica da administração, gerência, ou gestão se configura essencial em decorrência da contribuição de todas as ciências sociais. Analogamente, já não são suficientes as ênfases no conceito de racionalidade, em que a economia tem alicerçado seus esforços de descrever e explicar a realidade, ou as definições de personalidade ou de grupo, já que a psicologia e a psicologia social vêm questionando algumas de suas clássicas visões e a filosofia, antropologia e outras áreas do conhecimento criam equívocos e ilusões em função de abordagens legítimas e importantes, mas incapazes de dar sustentabilidade ao processo de desenvolvimento do planeta, da sociedade, das organizações e da vida humana.

Compreender a gestão, como área do conhecimento ou práticas con- 
ducentes a resultados esperados por indivíduos, grupos, organizações e sociedades, requer, portanto, visão holística da ciência social e, conseqüentemente, mudanças no porquê, no como, no para quem, do que se faz ou se deixa de fazer no cotidiano de nossas experiências, nos espaços que ocupamos.

Essas mudanças só se propiciam por meio da educação. Assim, as interseções entre administração e educação assumem posições claras, criando a expectativa de que as convergências entre ambas vão muito além do óbvio. Entende-se por óbvio o que facilmente se observa sem que para isso se exija elevado grau de percepção das interseções existentes entre as duas áreas de conhecimento, nos espaços em que ocorrem os fenômenos administrativos e educacionais.

\section{Construindo a Interrogação}

Muito se fala sobre a interdisciplinaridade e a indivisibilidade do conhecimento. Na prática, porém, torna-se extremamente difícil tratar as diversas áreas do conhecimento antifragmentariamente e, portanto, preservando a indissociabilidade entre todas elas. A própria epistemologia não tem dado conta dessa dificuldade.

Assim, há de se buscar sempre as associações entre as diversas áreas do conhecimento. Dentre elas, por exemplo, a intimidade visivelmente ostensiva entre administração e educação. O problema investigado neste trabalho pode, portanto, definir-se: qual a categoria fundamental capaz de demonstrar que o processo educacional está, em sua essência, ligado ao de gestão? Partiuse do pressuposto de que a amálgama entre ambos é a liberdade. Esse pressuposto não surge por acaso ou brota espontaneamente sem referências teóricas que permitam justificá-lo.

Em primeiro lugar, o conceito de liberdade emerge no campo teórico dos valores. Muitos autores o têm apontado como valor universal em todos os tempos e em todas as sociedades [Alberoni (2000), Capalbo (1990), Fraga (1994), Hessen (1974), Kidder (1994), Rescher (1968), Rokeach (1981)].

Em segundo, muitas abordagens teóricas na área educacional designam a liberdade como variável fundamental para se assegurar a qualidade do processo ensino-aprendizagem. Menciona-se a obra do educador brasileiro Paulo Freire em que a educação bancária, caracterizada como opressora, é substituída por práticas emancipatórias em que se garante a liberdade entre educadores e educandos. (FREIRE, 1986,1987 e 1998). Com ênfase na educação libertária, Bakunin (1989) também sinaliza para o fato de que sem liberdade não pode haver educação.

Linhares (s.d.), ao chamar a atenção para a liberdade a ser assegurada em educação, enfatiza-a na relação docente-discente em sala de aula. 0 
autoritarismo tem de ser substituído, nesse espaço, por uma constante ida e volta entre os atores do processo.

Por último, em busca da convergência entre administração e educação, importa ressaltar que os procedimentos de gestão no espaço educacional também têm de ser concebidos e implementados com a garantia da liberdade, sem a qual o processo ensino-aprendizagem não pode acontecer.

Vários autores da área de gestão têm chamado atenção para a liberdade nas práticas gerenciais. Galbraith (1995) tem enfatizado a prática da liberdade mediante conceitos de "envolvimento empregatício e organizações de alto envolvimento", que significam a possibilidade de implementação de práticas conducentes à participação efetiva dos indivíduos na gestão das organizações.

\section{Explicitando a Relevância}

A contemporaneidade aponta para a urgência de melhor entendimento da essência dos processos educacional e de gestão. A todo instante observa-se que a gestão constitui fator indispensável ao êxito de qualquer empreendimento humano. Adicionalmente, também se tem sinalizado para a urgência da melhoria do sistema educacional brasileiro e da qualidade de ensino em todos os níveis.

Vê-se, portanto, a relevância de estudos nos quais se busque entender o entrelaçamento entre as áreas de administração e de educação. Ressaltese que, além da relevância do tema, a experiência dos pesquisadores como docentes e consultores criou forte motivação para justificar o estudo.

\section{Desenhando os Caminhos Percorridos}

Ao final de vários cursos, por iniciativa destes autores, têm-se realizado avaliações por depoimentos verbais e escritos dos alunos. Assim, os procedimentos metodológicos seguidos para a elaboração deste trabalho incluíram algumas observações dos participantes de cursos ministrados pelos autores nos anos 2001/02, as quais foram, em parte, transcritas e inseridas no texto conforme os conteúdos revisados na bibliografia, com isso estabelecendo a ponte necessária entre teoria e prática.

Para construir essa ponte torna-se necessário uma imersão nos conteúdos libertários da educação e da administração para, em seguida, destacarlhes as convergências óbvias e não óbvias. 


\section{Educação: Essência e Desafios}

A educação, em qualquer nível ou espaço em que ocorra, tem sua essência com base em um tripé que, combinados os seus três eixos fundamentais, é capaz de manter de pé e com a cabeça erguida indivíduos, organizações, sociedades e nações.

O primeiro eixo consiste em compreender o processo educacional como interativo. A interação constitui condição absolutamente necessária para que se possa conceber a existência do processo educacional. Desejamos realçar que qualquer ação ou prática rotulada de educacional, sem preservação da interação dos indivíduos, transforma-se em patologia crônica, capaz de conduzir à morte os participantes do processo, já que as barreiras entre eles, intransponíveis e perpetuadas, inibem o crescimento do humano do ser.

Em linguagem fenomenológica, já nos apropriamos do conceito de educar que vai além de desenvolver educandos em seus aspectos físicos, intelectuais, morais e espirituais. Educar, portanto, se resume em contribuir para o desenvolvimento do humano do ser. As falas a seguir referem-se ora a um, ora a outro autor deste texto, em depoimentos espontâneos de seus respectivos alunos.

Sintamos um educando:

O professor em análise é muito bom, possui um bom método didático e se faz entender e simpatizar pelos seus valores pessoais ele acredita no módulo que prega o que torna confortável em sua posição de orientador. O módulo foi bastante agradável e de um aproveitamento total.

O segundo eixo do tripé diz respeito à definição do centro de ação educativa. Desloca-se o centro do educador para o educando, o que significa, conseqüentemente, construção do conhecimento, através de diálogo, discussão e comunicação livre e aberta, sem exposições inibidoras e narcísicas.

Em depoimento espontâneo, manifesta-se o aluno:

O estilo das aulas apresentadas pelo professor foge dos padrões e para melhor. A constante interação entre o professor e a turma proporcionou que os participantes refletissem com muita propriedade sobre os temas. A atenção do conteúdo das aulas foi muito grande.

Orientação em substituição à dirigibilidade constitui o terceiro eixo essencial. Não se trata de simples diabrura semântica; dirigibilidade implica dirigir em que se subentende forte relação de poder entre o educador, dirigente do processo educacional, e o educando, seu objeto e também sujeito na interação tradicionalmente estabelecida. Assim, importa, sobremaneira, que 0 aluno seja o sujeito do processo. 
A fala a seguir ilustra a teoria: "O alto grau de discussão da matéria e a constante comparação das idéias expostas com a experiência dos alunos favoreceram uma compreensão enriquecida"

Orientação incorpora a idéia de emulação, provocação, sinalização de caminhos que relações de poder jamais assumirão a clássica dicotomia comando e subordinação, em que papéis se mantêm inalterados e permanentes, mesmo sem conflitos visíveis em aquiescência mútua. Na orientação, já que relações de poder, inerentes à condição humana, se criam desde as relações interpessoais, comando e subordinação se alteram em dinâmica de colaboração, na qual o educador-orientador se submete, aprendendo e reaprendendo com o educando-orientando que, por sua vez, comanda seu próprio destino, ensinando e aprendendo com o educador.

A fala, pelas manifestações a seguir, fortalece o exposto:

Excelente relacionamento com a turma, valorizando as colocações dos alunos, extraindo o que os alunos têm de melhor. Metodologia excelente!

A variável "habilidade de estimular o envolvimento do grupo" foi a mais importante e que se destaca na avaliação do professor. Nota 10, ele tem habilidade de incentivar e destacar os pontos positivos das pessoas, mesmo identificando as limitações dos alunos. Professores como ele é que fazem a diferença no ensino, na troca, na aprendizagem e no sucesso da carreira de um profissional.

Desse modo, ênfases incidirão na intensidade e qualidade da interação, na educação e, conseqüentemente, no ensino centrado no educando e na orientação, substituindo a dirigibilidade, alicerçando-se na abordagem construtivista dos processos educacional, ensino-aprendizagem e construção do conhecimento em que se apontam como os iluminados da teoria, Piaget, Vygotsky e Wallon, além de outros seguidores.

\section{Construtivismo em Resumo}

Jean Piaget, um dos maiores cientistas do século XX, preocupou-se em compreender e analisar como se dá o processo de aquisição do conhecimento pelo indivíduo, criando a epistemologia genética, na qual o autor descreve e explicita as várias etapas do processo de aprendizagem conforme as fases do desenvolvimento humano.

O pensamento piagetiano rompe com o tradicional, por demonstrar 
que o conhecimento não se adquire por simples transferência de algo de alguém para outrem. Ao contrário, se constrói e se molda, em processo dinâmico e contínuo entre os participantes do processo educacional. Rompe ainda com a convicção de que o conhecimento decorre exclusivamente de fatores exógenos e, portanto, dependente apenas de estímulos externos e, assim, condicionado unicamente pelo educador. Piaget rompe igualmente com conclusões que afirmavam que o potencial humano e as estruturas cognitivas de cada um, durante muito tempo, foram consideradas inatas e, conseqüentemente, predeterminadas e prontas.

Assim, os teóricos tradicionais entendiam o conhecimento como processo transmissível, concretizado sempre de fora para dentro em toda e qualquer situação e nível de ocorrência, ao passo que a teoria educacional moderna baseia-se em visão construtivista do conhecimento em que a aprendizagem se constrói, de dentro para fora, intransferível e, principalmente, em busca da liberdade e emancipação do humano do ser.

A despeito da individualização, intransferibilidade e interioridade do processo de aquisição do conhecimento, a tarefa não é individual e egocêntrica. Importante acrescentar que o indivíduo não está só no mundo. A aprendizagem que realiza terá de ser compartilhada com outros com urgência e vigor. A aprendizagem individual se socializa e contribui para a transformação social e não apenas a que o indivíduo percebe em si mesmo. Transforma em educador o educando, com outros grupos, organizações e sociedade.

\section{Educação Libertária versus Opressora}

Interrogamo-nos insistentemente. Como compreender e aceitar uma educação que admite a vileza de um povo marginalizado e excluído, sem que educadores, políticos, governantes e gestores ajam ininterrupta e solidamente para reverter essa situação? Como permitir e até estimular que a sociedade se encontre na passividade, a não ser para oprimi-la, abortando-lhe todo e qualquer movimento libertário?

Responder a esses questionamentos requer apreensão de toda e qualquer ação educacional como prática da liberdade. Como Freire (1996), apossamo-nos do pressuposto básico de que o homem foi criado para se comunicar com seus semelhantes e, assim, como educador, suas palavras não poderão ser desprovidas de sentimentos; de pensamento e emoção; de competência; de senso de justiça; de amor, respeito e solidariedade. Dessa forma, a educação libertária se tornará o veículo capaz de conduzir à transformação global do homem e da sociedade.

Até aqui olhamos para o profissional da educação que, convicto de 
ideais libertários, prega e age consoante suas convicções. Não lhe pode bastar, porém, seu ideário se houver a passividade daqueles com quem pretende se comunicar por meio do processo educacional.

Desse modo, a educação não se reduz à busca da eficácia do processo ensino-aprendizagem em loci' formalmente instalados. Há de se pensar em educação que abomine o escândalo da exclusão, marginalização, passividade e mordaça.

Somente se concretiza a educação libertária em plenitude em sociedade na qual existam condições econômicas, sociais e políticas de existência em liberdade e, enfaticamente, de padrões libertários de gestão.

\section{Administração e Educação}

O processo educacional não acontece fora de sua dimensão espacial e temporal. Como se demonstrou, o processo interativo ensino-aprendizagem requer atores que, na metáfora cênica, terão de ocupar palco adequado e tempo propício a seu desenvolvimento. Esse palco, como no teatro, pode ocorrer em espaço aberto sem arquitetura sofisticada, não dispensando, porém, definição de papéis, direção, correção de desvios e inadequações, iluminação e transparência de atuação, scripts criativos e inovadores e, contundentemente, interação com públicos, clientes e usuários.

Torna-se fácil perceber, portanto, que grande parte do êxito do processo educacional resulta de adequados modelos de gestão em que se incluem processos de modelagem organizacional; processos decisórios capazes de contemplar, além do racional, o não-racional nas escolhas realizadas por indivíduos, grupos e organização; visão estratégica de missões, objetivos e cenários futuros; busca e manutenção de valores que, alicerçados no bem comum, assegurarão participação e liberdade na vida social.

Pelo exposto, clarifica-se a convergência entre administração e educação, visto que a tarefa de educar requer estruturas, processo decisório, tecnologia de informação e sistemas de reconhecimento ajustados de forma harmônica e interdependente. A despeito da importância do processo de gestão para a realização do ensino, ele por si só ou em si mesmo não garante o sucesso do processo educacional. Desse modo, só se assegura o sucesso da aprendizagem quando há coerência entre o processo de gestão e os objetivos a serem alcançados.

\section{Gestão: Essência e Desafios}

Pelos tempos, o pensamento administrativo evolveu a preocupação 
única e exclusiva com os instrumentos de gestão para a observação de que os instrumentos têm de ser servos e não senhores. Embora já haja conscientização em alguns meios acadêmicos dessa evolução, as práticas diuturnas de gestão ainda se sustentam em sua vertente tradicional, em que o burocrático emperra 0 atingir de fins; o legal predomina sobre o real; a prática ofende os discursos tonitroantes; a hierarquia vence o holístico; e, principalmente, o controle sufoca a autogestão.

Assim, a evolução da teoria administrativa apresenta busca contínua de organizações em que o indivíduo deveria assumir o centro das preocupações das ações de seus dirigentes pelos processos de descentralização, permitindolhe maior participação no processo de gestão. Esse fato não decorre da simples utilização de instrumentos administrativos, ao contrário, requer preocupação com a formação de valores por intermédio de ações educacionais que não só permitirão ambientes organizacionais em que o indivíduo poderá atuar em sua plenitude, como também habilitarão as organizações a contribuir na construção de sociedades mais justas. Dessa forma, a compreensão de como os valores individuais condicionam decisões e ações nas organizações a partir de sua construção, desconstrução e reconstrução é de fundamental importância.

\section{Gestão Libertária e Gestão Opressora}

Para se chegar ao conceito de gestão libertária é necessário revisar-se os próprios conceitos de gestão e administração.

A gestão contemporânea, sem se afastar da definição de objetivos a serem alcançados por meio de instrumental eficiente, incorpora outras variáveis, constantemente identificadas por vários autores como fundamentais para a compreensão do cotidiano organizacional, tais como, a título exemplificativo, estilos de liderança Mintzberg (1973), desenvolvimento de equipes Moscovici (1998), processo decisório [Pereira e Fonseca (1997)], poder, processos de mudança [Motta (1997)], planejamento estratégico Ansoff (1983)], valores Rescher(1969), ambiência Lawrence e Lorsch (1967), além de outras.

Esse conceito amplo e abrangente de gestão permite a estudiosos e gestores visão mais integrada das organizações como espaços em que o processo administrativo se instala. Essa visão é elástica e pode se estender para fora da organização.

A abordagem contingencial da gestão enfatiza esse aspecto Lawrence e Lorsch (1967). Essa digressão, contudo, não satisfaz porque não estimula e propicia o processo de construção e reconstrução de valores conducentes à liberdade e solidariedade, aqui considerados valores universais inerentes à condição humana e, conseqüentemente, buscados por indivíduos, organizações e segmentos da sociedade. 
Introduzimos, portanto, o conceito de gestão libertária, a fim de dar sólido respaldo teórico a este trabalho. O cerne desse conceito é a gestão política dos indivíduos pela existência de valores que propiciem participação consciente na transformação da realidade organizacional e, como conseqüência, social.

A existência desses valores individuais é o único caminho responsável pelo desenvolvimento e consolidação de mudanças organizacionais capazes de levar à gestão libertária, partindo-se do pressuposto de que essa transformação só se conquista por meio da liberdade e da solidariedade. Daí a necessidade de transformação do processo de formação de gestores pela educação libertária, que visa a alcançar o "estado de felicidade organizacional" mesmo considerando a relatividade desse conceito.

Desse modo, seja do ponto de vista da ciência política, filosofia e psicologia, a externalização da felicidade está intimamente atrelada aos valores individuais.

A felicidade plena será atingida na medida em que o processo de busca de valores inerentes à condição humana seja permanente, a fim de possibilitar o exercício desses valores.

Decorre do que se expôs que as escolhas dos instrumentos de gestão e sua implementação estão condicionadas por valores alicerçados em vivências associadas ao prazer e à dor. Explica-se, portanto, que formas de gestão se apresentem bastante diferenciadas.

Isso significa que essa diferença não garante o comprometimento de indivíduos e o desenvolvimento de organizações justas e humanas, nem, portanto, a criação do estado de felicidade organizacional. Assim, esse estado só se concretiza quando e se os valores se referem à liberdade e à solidariedade.

Com base nisso, tomemos como exemplo o crescente interesse pelo que se tem denominado universidade/educação corporativa, como instrumento capaz de formar indivíduos aptos a intervir em sua realidade de trabalho. Tal interesse tem se justificado a partir da própria crítica ao sistema universitário existente.

O sistema corporativo que tem em sua concepção o objetivo de melhorar as competências individuais corporativas, retira do indivíduo sua capacidade de reflexão mais ampla, tornando-o mais alienado quanto à importância do papel social do trabalho que exerce e, portanto, incapaz de interferir na realidade para transformá-la, repetindo-se, assim, o modelo de educação bancária definido por Freire (1987).

Esse sistema de ensino visa a reforçar valores das elites corporativas de forma a extrair maior produtividade de seus colaboradores, visando unicamente ao lucro, como assim o fizeram quando da aplicação das teorias das escolas comportamentais e de relações humanas, conforme Morgan (1996). 
Assim, amplia-se a alienação, impedindo-os de serem sujeitos de sua própria história em Sartre (1997).

A formação de gestores e indivíduos livres, participantes e comprometidos com resultados éticos e úteis a si próprios, à organização em que atuam e à sociedade, consiste na substituição das práticas características da educação bancária pela libertária.

O que se observa nas práticas pedagógicas em todos os níveis, desde a educação infantil até a pós-graduação de mais alto grau, é a repetição de ações tradicionais criadas e perpetuadas pelas elites dominantes. Na realidade, as universidades corporativas, costumeiramente apresentadas como alternativas transformadoras da educação, não vão além de representar os valores das elites.

O mesmo tem ocorrido nas universidades públicas ou particulares. Isso, porém, não constitui barreira às práticas educacionais libertárias, desde que venham a predominar no processo educacional, nas relações educadoreducando dentro e fora dos espaços formais de aula, e nos valores inerentes à condição humana: liberdade, solidariedade e autonomia.

Assim, educar e ensinar, assentados em novos valores e novos pilares de visão do mundo, do homem e da organização requer: compreensão e manutenção do processo interativo do educador com o educando; rigor metodológico; pesquisa; respeito aos saberes e aos educandos independentemente de conhecimentos prévios ou tipos e graus de inteligência; criticidade de forma a assegurar a capacidade crítica sem julgá-la pura ingenuidade, estética e ética, "decência e boniteza de mãos dadas" Freire (1996, p.36): corporificação das palavras pelo exemplo.

Em sua essência, educação libertária baseia-se no ensino antiautocrático integral de maneira a não se impor limites às possibilidades de aprendizagem, além de ser antidiscriminatória em todos os sentidos. A educação libertária deve ser entendida a partir do desejo de solidariedade em todos os seres humanos, já que qualquer tipo de preconceito e diferenciação no processo educacional acentua a falta de liberdade, solidariedade entre os membros da sociedade e, conseqüentemente, dentro das organizações.

Persistem, portanto, desafios ao gestor moderno e empreendedor. Dentre eles assume relevância impostergável a adoção de práticas libertárias de gestão, o que só se poderá alcançar por meio de processos igualmente libertários na formação de gestores.

\section{Reflexão sobre Modelo de Gestão em Educação}

Para o florescimento da educação libertária urge a concepção de modelo de gestão no espaço educacional, em que igualmente se preserva a 
liberdade. Esse modelo deverá basear-se em algumas diretrizes que aqui podem ser enunciadas.

a) Integração dos espaços administrativo e educacional

Significa a atuação harmônica entre o substantivo e o instrumental, a fim de que os procedimentos administrativos jamais contribuam para a ineficácia do ensino.

b) Ênfase na qualidade do ensino

Só por práticas libertárias de gestão pode-se assegurar reflexão crítica, aceitação do novo, comportamento ético, rigor metodológico, respeito ao saber dos educandos e reconhecimento da identidade cultural.

c) Preservação do humano do ser

Em que a gestão considere permanentemente valores indispensáveis à convivência entre docentes e discentes, chefes e subordinados e entre pares, destacando-se o espírito de solidariedade, respeito e compaixão, valores necessánios à construção de uma sociedade mais igualitária e, portanto, menos injusta.

Figura 1 - Representação Gráfica do Modelo

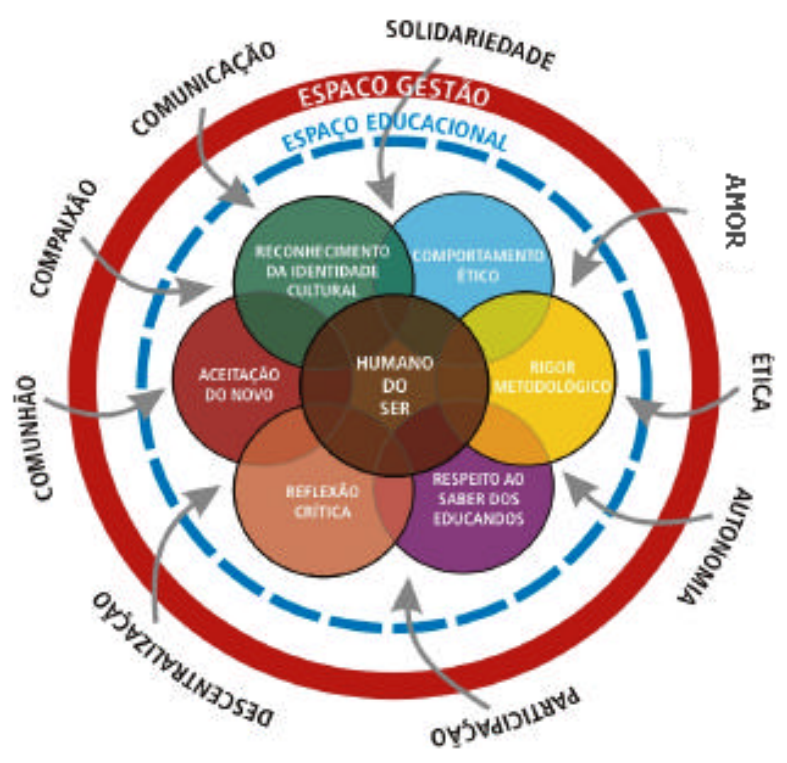

É importante frisar que o modelo aqui proposto poderá correr 0 risco, como tantos outros, de ser implementado de modo mecanicista. Para que isso não ocorra, múltiplos atores do processo educacional e de gestão terão de construir e preservar continuamente valores essenciais ao ser humano. Assim, assegurando o essencial do humano do ser.A AVALAÇÃO INSTIE 


\section{Caso da SME}

Com o objetivo específico de estudar o tema na área de gestão educacional e buscar as convergências entre administração e educação, os autores realizaram pesquisa na SME/RJ com o objetivo de ilustrar o presente trabalho, tendo em vista as reformulações postas em prática no modelo de gestão da secretaria. Desse modo, os autores tiveram a oportunidade de aplicar suas reflexões nas transformações em curso.

O universo foi constituído por seis escolas distribuídas em quatro Coordenadorias Regionais de Ensino (CRE). A escolha das unidades escolares (UE) foi determinada por critérios pragmáticos de acessibilidade.

Os sujeitos da pesquisa foram selecionados mediante procedimentos acidentais, constituindo-se a amostra de 11 dirigentes, 6 diretores, 60 professores, 63 alunos e 33 responsáveis.

O novo modelo organizacional e de gestão em processo de implantação na SME/RJ ainda não transformou a secretaria em espaço aberto no sentido de que o cidadão, o aluno, o professor, o funcionário, a escola e a comunidade se mesclem com inteira liberdade aos atores centrais da organização que, a despeito de todos os avanços implementados - descentralização, gestão participativa, integração e mudança de valores -, estejam consciente ou mesmo interessados em realizá-lo.

Verificou-se que no ensino municipal do Rio de Janeiro as mudanças não têm produzido melhoria em sua qualidade e que a avaliação positiva do processo de mudança, que se tem feito até aqui com base em indicadores facilmente observáveis e de acordo com a ótica de seus idealizadores, não é compartilhada pelos que atuam na ponta do sistema.

Identificamos questões educacionais que extrapolam o sistema burocrático governamental e que nos permitiram a avaliação da real efetividade das ações no âmbito da secretaria.

Dentre essas questões surgem dramaticamente:

- A captura das unidades escolares por agentes da violência urbana impedindo que os Conselhos Escola-Comunidade reflitam a realidade da construção e desenvolvimento da cidadania. Têm sido inúmeros os exemplos em que unidades escolares situadas em determinadas áreas urbanas são forçadas por grupos marginalizados da sociedade a fechar suas portas, impedindo 0 exercício de suas atividades normais. Isso, sem dúvida, acontece na cidade do Rio de Janeiro, em outras regiões do país e, certamente, nos demais países latino-americanos.

- Os dados oficiais referentes à evasão escolar mascaram-se por iniciativas como aprovação automática. 
- Inexistência de análise qualitativa das estatísticas oficiais como, por exemplo, as referentes ao retorno à sala de aula de professores que passaram por capacitação.

- Os programas de aceleração de aprendizagem perdem sua eficácia na medida em que os critérios para a formação de turmas não são diferenciados.

- O processo de descentralização promovido pela SME/RJ ainda mantém a concepção de outorga e concessão de poder dentro dos limites definidos pelo centro, deixando-se de caracterizá-lo como processo de conquista social. Como ilustração tem-se observado que o processo democrático de escolha de diretores das unidades escolares ainda é fortemente controlado por órgãos centrais do sistema.

- A dificuldade de participação dos diversos atores sociais nas decisões do cotidiano escolar em virtude, em grande parte, da cultura centralizadora e predominantemente autoritária da sociedade brasileira, fruto das poucas experiências democráticas vividas pela sociedade, mesmo em unidades escolares onde já se instala processo eleitoral democrático, nas quais ainda se observam comportamentos semelhantes aos do processo eleitoral brasileiro.

- Apesar dos esforços em prol da descentralização, as UE's ainda padecem da ausência de autonomia financeira, administrativa e até mesmo pedagógica.

- Ausência de integração do pedagógico com o gerencial, resultante em grande parte de falta de programas de capacitação de gestores educacionais.

- Precariedade de condições físicas de trabalho.

- Grande número de alunos concluintes do primeiro segmento do ensino fundamental inabilitado à leitura e à escrita fluentes, o que revela a precariedade da qualidade de ensino.

A manutenção em prol da cidadania intensa exige atividade participativa de todos, notadamente dos que detêm poder decisório, cujas decisões produzem efeitos muitas vezes definitivos sobre indivíduos-cidadãos e segmentos, inclusos ou exclusos da comunidade.

Assim, participação imposta não significa participação. Na comunidade escolar ou em qualquer outro espaço, a participação de professores, alunos e funcionários no processo decisório, tornada obrigatória por detentores de maior parcela de poder, não significa construção da cidadania.

O espaço educacional requer, portanto, rupturas ousadas na gestão do sistema educacional, a fim de se impedir ações por atores desqualificados. Há de se saltar da administração escolar - aprisionante, dominadora e castradora - para a gestão escolar libertária, inovadora e empreendedora. 
Vários fatores contribuem para o insucesso no processo de implementação da mudança organizacional. Ressalte-se primeiramente a falta de visão dos gestores de que qualquer modelo previamente construído representa algum reducionismo no universo de variáveis que compõem a organização.

Em segundo lugar, a concepção de modelos bastante abrangentes, por integrarem o maior número possível de variáveis, não direciona e nem garante a transformação organizacional por ser incapaz de dar conta da subjetividade humana a valores individuais.

A questão do poder emerge também como maior entrave a qualquer tentativa de descentralizar o processo decisório, caso não se lide com ela de maneira objetiva, transparente e sem subterfúgios. Ressalte-se ainda que a própria descentralização já incorpora a transferência de poder para não reduzi-la a processo simplista de descentralização de atividades.

Neste trabalho, o óbvio torna-se ainda mais óbvio: mais difícil que construir o presente é desconstruir o passado. Perpetua-se a indagação: Por que essa dificuldade? Que múltiplas causas levam a esse obstáculo?Que estratégias têm sido utilizadas para superá-la?

Não restam dúvidas. Os números, as falas, os discursos, as ações da $\mathrm{SME} / \mathrm{RJ}$ apontam em direção à natureza e ao cerne da arquitetura organizacional: sua dimensão político-ideológica. Assim, as teorias da modelagem organizacional, ao considerarem em seus modelos as características sócio-técnicas, reduzem a questão por deixar de enfatizar o mais relevante: 0 enfoque sociopolítico ideológico.

\section{Além das Convergências à Guisa de Conclusão}

Inquestionável a associação entre administração e educação. Em primeiro lugar, porque se o processo educacional ocorre, como já se demonstrou em espaços organizacionais, algum modelo de gestão torna-se indispensável.

Ademais, convencido ou não, consciente ou inconsciente de seu papel, o gestor desempenha função educacional de extrema importância. Não é ele quem lida com seus superiores, não só para prestar-lhes conta, mas principalmente para alertá-los e influenciá-los em suas decisões? Não é ele quem também interage com seus pares em processo de contínua interação que poderá maximizar ou não seus interesses pessoais ou de classe? Ainda mais, e quiçá, principalmente, não é ele quem se comunica com seus subordinados, dando-lhes ordens sem se aperceber da importância do impacto ao fazê-lo ou ao contrário orientando-os e influenciando-os em seu crescimento profissional e pessoal? Por tudo isso, não há como se dissociar a administração da educação. 
A questão, porém, vai além das possíveis convergências entre ambas.

Não é difícil abordar-se cognitivamente uma e outra. Apresentam cada uma conceitos, métodos e metodologias e práticas não muito complexas para seus estudiosos.

Torna-se, porém, muito difícil ir além dessa compreensão porque 0 cognitivo não basta ao educador e ao gestor para transformar sociedades, comunidades e o coletivo. É preciso ir além das convergências.

Esse além só se visualiza nos processos educacional e gerencial se se exerce a liberdade de escolhas, de ações e do que se possa considerar felicidade.

Assim, à guisa de conclusão, o que realmente importa, seja na administração ou na educação e na integração das duas ciências, é a prática da liberdade.

\section{Referências}

ALBERONI, F. Valores: o bem, o mal, a natureza, a cultura, a vida. Tradução de Y. A. Figueiredo. Rio de Janeiro, RJ: Rocco, 2000.

ALVES, N.; VILLARDI, R. Múltiplas Leituras da Nova LDB. Rio de Janeiro, RJ: Gualitymark Dunya, 1997.

ANSOFF, H. I. Administração estratégica. São Paulo, SP: Atlas, 1983.

BAKUNIN et al. Educação Libertária. Porto Alegre: Artes Médicas, 1989.

CAPALBO, C. Fenomenologia e educação. In: FÓRUM EDUCACIONAL, jun./ ago. Anais... Rio de Janeiro, 1990.

FORTUNA, M. L. A Gestão escolar e subjetividade. Niterói: Intertexto, 2000.

FRAGA, V. F. Gestão pela formação humana: em tecnologia avançada. Rio de Janeiro, 1994. Tese (Doutorado em Educação). Universidade Federal do Rio de Janeiro.

FREIRE, P. Pedagogia da autonomia. Rio de Janeiro, RJ: Paz e Terra, 1998.

. Pedagogia do oprimido. Rio de janeiro, RJ: Paz e Terra, 1987.

$\overline{1} \overline{9} \overline{6}$.

. Educação como prática da liberdade. Rio de janeiro: Paz e Terra,

GALBRAITH, J. Organizando para competir no futuro: estratégia para gerenciar o futuro das organizações. São Paulo,SP: Makron Books, 1995. 
HESSEN, J. Filosofia dos valores. Coimbra: Armênio Amado, 1974.

KIDDER, R. Shared values for a troubled word. San Francisco: Jossey-Bass, 1994.

LAWRENCE, P. R; LORSH, J. W. Organization and enviroment. Boston: Harvard Business School, 1967.

LINHARES, C. F. S. A escola e seus profissionais. Rio de Janeiro, RJ: Agir, s.d.

MARTINS, J.do P. Administração escolar. São Paulo, SP: Atlas, 1999.

MINTZBERG, H. Estrutura e dinâmica das organizações. Lisboa: Dom Quixote, 1995.

MORGAN, G. Imagens da organização. Rio de Janeiro, RJ: Atlas, 1996.

MOSCOVICI, F. Renascença organizacional. Rio de Janeiro, RJ: Livros Técnicos e Científicos, 1998.

MOTTA, P. R. Gestão contemporânea: a ciência e a arte de ser dirigente. Rio de Janeiro, RJ: Record, 1995.

. Transformação organizacional: a teoria e a prática de inovar. Rio de Janeiro, RJ: Quality Mark, 1997.

NOT, L As pedagogias do conhecimento. São Paulo, RJ: Difel, 1981.

PEREIRA, M. J. L B. e FONSECA, J. G. M. F. Faces da decisão: as mudanças de paradigmas e o poder da decisão. São Paulo.SP: Makron Books, 1997.

PIAGET, J. Para onde vai a educação? Rio de Janeiro, RJ: José Olympio, 1973.

RESCHER, N. I ntroduction to value theory. New Jersey, Englewood Clifs: Prentice-Hall, 1969.

ROKEACH, M. Crenças, atitudes e valores: uma teoria de organização e mudança. Tradução de Ângela Maria Barbosa. Rio de Janeiro, RJ: Interciência, 1981.

SARTRE, J. P. 0 ser e o nada: ensaio de ontologia fenomenológica. Petrópolis: Vozes, 1997.

SESC (SERVIÇO SO CIALDO COMÉRCIO). Departamento Nacional. Educação: propostas pedagógicas. Rio de Janeiro, RJ: SESC, 2000.

TACHIZAWA, I.; ANDRADE, R. B. G estão de instituições de ensino. Rio de 
Janeiro, RJ: Fundação Getulio Vargas, 1999.

TAILE, I. de la. PIAGET, J. VYGOTSKY, L S.. Teorias psicogenéticas em discussão. São Paulo, SP: Iummus, 1992.

VIEIRA, P. R. CARDOSO, A. S. R. A Secretaria Municipal de Educação do Rio de Janeiro: da Administração Escolar à Gestão Escolar. Rio de Janeiro: Fundação Escola do Serviço Público do Estado do Rio de Janeiro, 2000. (Coletânea do 7ํㅡㄹ Concurso Casos e Textos).

VYGOTSKY, L S. Pensamento e linguagem. São Paulo, SP: Martins Fontes, 1995.

Recebido em 6/10/03

Aprovado em 28/11/03 